\title{
Assessment of the immune capacity of mammary epithelial cells: comparison with mammary tissue after challenge with Escherichia coli
}

\author{
Juliane GÜNTHER $^{1}$, Dirk KoCZAN ${ }^{2}$, Wei YANG ${ }^{1,3}$, Gerd NÜRNBERG ${ }^{1}$, \\ Dirk RePsilber ${ }^{1}$, Hans-Joachim SChUBERTh ${ }^{4}$, Zaneta PARK ${ }^{5}$, Nauman MAQBOOL ${ }^{6}$, \\ Adrian MolenaAR ${ }^{6}$, Hans-Martin Seyfert ${ }^{1 *}$ \\ ${ }^{1}$ Research Institute for the Biology of Farm Animals (FBN), Molecular Biology Research Unit, \\ Wilhelm-Stahl-Allee 2, 18196 Dummerstorf, Germany \\ 2 Institute for Immunology, Steinbeis Transfercenter for Proteome Analysis, \\ Core Facility for Transcriptome Analysis, Schillingalle 70, 18055 Rostock, Germany \\ ${ }^{3}$ Present address: Department of Anesthesiology, Duke University Medical Center, Durham NC 27710, USA \\ ${ }^{4}$ University of Veterinary Medicine, Immunology Unit, Bischofsholer Damm 15, 30173 Hannover, Germany \\ ${ }^{5}$ AgResearch, Palmerston North, New Zealand \\ ${ }^{6}$ AgResearch, Ruakura Research Centre in Hamilton, New Zealand
}

(Received 25 June 2008; accepted 24 March 2009)

\begin{abstract}
We examined the repertoire and extent of inflammation dependent gene regulation in a bovine mammary epithelial cell (MEC) model, to better understand the contribution of the MEC in the immune defence of the udder. We challenged primary cultures of MEC from cows with heat inactivated Escherichia coli pathogens and used Affymetrix DNA-microarrays to profile challenge related alterations in their transcriptome. Compared to acute mastitis, the most prominently activated genes comprise those encoding chemokines, interleukins, beta-defensins, serum amyloid A and haptoglobin. Hence, the MEC exert sentinel as well as effector functions of innate immune defence. E. coli stimulated a larger fraction of genes (30\%) in the MEC belonging to the functional category Inflammatory Response than we recorded with the same microarrays during acute mastitis in the udder $(17 \%)$. This observation underscores the exquisite immune capacity of MEC. To more closely examine the adequacy of immunological regulation in MEC, we compared the inflammation dependent regulation of factors contributing to the complement system between the udder versus the MEC. In the MEC we observed only up regulation of several complement factor-encoding genes. Mastitis, in contrast, in the udder strongly down regulates such genes encoding factors contributing to both, the classical pathway of complement activation and the Membrane Attack Complex, while the expression of factors contributing to the alternative pathway may be enhanced. This functionally polarized regulation of the complex complement pathway is not reflected in the MEC models.
\end{abstract}

mastitis / transcriptome profiling / immune capacity / mammary epithelial cell

\section{INTRODUCTION}

Infection of the udder (mastitis) is the most costly disease of diary cattle $[24,26]$. A variety

\footnotetext{
* Corresponding author: Seyfert@fbn-dummerstorf.de
}

of different bacteria and fungi cause mastitis. The etiology of the infection influences the outcome. Gram negative coliform bacteria most frequently cause an acute inflammation and eventually severe mastitis [7], while gram

This is an Open Access article distributed under the terms of the Creative Commons Attribution-Noncommercial License (http://creativecommons.org/licenses/by-nc/3.0/), which permits unrestricted use, distribution, and reproduction in any noncommercial medium, provided the original work is properly cited. 
positive bacteria, such as Staphylococcus aureus and Streptococcus uberis may cause persistent, almost chronic infections, with pathogens surviving inside host cells [12]. These pathogens very often cause only mild inflammations $[2,8,10]$. The mechanisms underlying these different host responses towards the various pathogen species are largely unknown. The persisting infections cause large financial losses $[13,29]$. Hence, it would be highly desirable to understand the mechanisms precluding an effective immune defence against those pathogens causing subclinical mastitis.

Genome wide transcriptome and proteome profiling techniques are now available to monitor all infection related changes in the transcriptome and proteome, promising deep insight into the molecular mechanisms of host-pathogen interactions. Application of these sensitive analytical tools mandates using strictly controlled experimental conditions to generate meaningful results. Several groups have established experimental conditions to reproducibly infect lactating udders from cows with Escherichia coli or S. aureus pathogens $[2,23,30]$. However, models based on the infection of live cows suffer from variations introduced by the host animal's individuality [7]. Moreover, the udder is a complex organ, composed of a variety of cell types which may all contribute differentially to the immune competence of the udder [22].

Relevant model cells for the study of host pathogen interaction are much easier to standardise, promise better reproducibility and eventually allow the analytical dissection of molecular mechanisms. Regarding immune defence against mastitis, the immune relevance and capacity of milk cells including sentinel cells and granulocytes has been extensively characterized $[6,7,9,16,19]$. However, the immune relevance of mammary epithelial cells (MEC) has only recently been recognized [15, $17,28]$. The principle function of MEC is milk formation during lactation. Thus, these cells are the dominant cell type in the healthy, uninfected milk parenchyma and are most likely the first cells to be confronted with a pathogen, once this has entered the milk parenchyma.

Analyzing primary isolates of bovine mammary epithelial cells (pbMEC) allows examining the MEC specific contribution to the immune capacity of the udder. The principle immune relevance of such cultures has recently been established by the demonstration of inflammation dependent enhanced expression of a variety of candidate genes for immune reactions, like cytokines, chemokines, TLR receptors and betadefensins [17, 28, 34, 35]. However, there are no reports describing the global transcriptional response of pbMEC after a pathogen challenge.

We used here the world wide available Affymetrix microarray technology to characterize immune responsiveness after stimulating pbMEC with preparations of heat killed pathogenic $E$. coli bacteria. We compared the lists of regulated genes from these experiments to those obtained from udders featuring acute mastitis, after experimental infection of previously healthy, lactating udders with live $E$. coli pathogens. Our data thus not only allow monitoring the immune capacity of a highly relevant MEC model but also to delineate some regulatory limitations of the pbMEC model to reflect the complex response of immunological regulation circuits operating in the udder in response to invading pathogens.

\section{MATERIALS AND METHODS}

\subsection{Animals}

Four first lactation Holstein cows in the fourth month of lactation were experimentally infected with the mastitis causing E. coli pathogen strain 1303 . Details of the experimental udder infections, the clinical aspects and sample collection have been previously described [18]. Briefly, udder quarters were infected with $500 \mathrm{CFU}$ E. coli, strain 1303. One quarter from each animal was kept as an uninfected control. All infected quarters featured the typical clinical symptoms of acute mastitis after $24 \mathrm{~h}$, when the animals were culled. Udder tissue samples were collected aseptically within 5 to $10 \mathrm{~min}$ after killing the cow and snap frozen in liquid nitrogen.

\subsection{Cell culture and challenge with pathogens}

pbMEC were prepared from the udders of healthy, uninfected lactating cows. They were isolated and cultured in RPMI 1640 medium (Biochrom AG, Berlin, Germany), supplemented with prolactin, hydrocorti- 
sone, insulin and 10\% FCS as described [34]. Fibroblasts were removed by selective trypsinization (Trypsin-EDTA $(0.25 \% / 0.02 \%)$, Biochrom AG) during the following days. Residual colonies of fibroblasts were eventually manually scraped off.

E. coli pathogens, strain 1303 were grown $\left(37^{\circ} \mathrm{C}\right)$ in TY broth to the logarithmic phase of culture growth (Optical Density at $600 \mathrm{~nm}\left[\mathrm{OD}_{600}\right] \quad 0.5, \sim 5 \times$ $10^{7} / \mathrm{mL}$ ). Plating of dilution series were used to calibrate cell counts from the OD readings. Incubating the cells for $1 \mathrm{~h}$ at $60^{\circ} \mathrm{C}$ killed all cells, as verified by control plating. Subsequently, the cells were spun down, washed twice with RPMI 1640 and resuspended herein at a density of $5 \times 10^{8} / \mathrm{mL}$. Aliquots were stored frozen at $-20{ }^{\circ} \mathrm{C}$.

To challenge pbMEC with heat killed bacteria, we seeded $5 \times 10^{6}$ pbMEC into a $9 \mathrm{~cm}$ dish, coated with collagen R (Serva, Heidelberg, Germany). Eventually, all the pbMEC were lifted off with trypsin and washed twice in RPMI+ growth medium. The entire suspension was distributed into 6 wells of a collagen coated 6 well plate. This ensured that the cells were plated at high densities to deliberately avoid cell proliferation. The cells were allowed to attach for $24 \mathrm{~h}$. Subsequently, some wells were challenged with $10^{7}$ heat killed $E$. coli $1303 / \mathrm{mL}$, equivalent to a multiplicity of infection (MOI) of approximately 30 . Other cells were kept as unchallenged controls. The cells were collected after $24 \mathrm{~h}$, washed three times with phosphatebuffered saline (PBS) to remove the bacteria. Total RNAwas prepared. The experiment was repeated three times using pbMEC isolated from three different cows.

\subsection{Immunocytochemistry/ Immunohistochemistry with pbMEC}

For immunocytochemistry, pbMEC were seeded into dishes containing collagen coated coverslips. After two days of culture growth, coverslips were washed three times with PBS and fixed with ice-cold methanol $\left(10 \mathrm{~min},-20^{\circ} \mathrm{C}\right)$. Anti-cytokeratin 18 (clone KS-B17.2, Sigma-Aldrich, Munich, Germany) and anti-alpha-smooth muscle actin (clone 1A4, Sigma) antibodies were applied as prescribed by the manufacturer. Bound antibodies were visualized with fluorescein isothiocyanate (FITC)-labeled secondary antibody (Sigma). Detection of alpha-smooth muscle actin in serial sections from udder tissue was done as previously described [18].

\subsection{Quantitative real-time PCR (qRT-PCR)}

We used TRIZOL (Invitrogen, Karlsruhe, Germany) for RNA extraction and the LightCycler instrument with the SYBR Green plus reagent kit (both from Roche, Basel, Switzerland) for qRTPCR quantification of messenger RNA (mRNA) copy numbers, essentially as described [11]. Sequences of the oligonucleotide primers used are given in Supplementary Table S1 ${ }^{1}$.

\subsection{Microarray hybridizations}

\subsubsection{RNA extraction}

We used the RNeasy kit for RNA extraction and followed the general procedures as prescribed by the manufacturer (Qiagen, Hilden, Germany). Mammary tissue (50 to $200 \mathrm{mg}$ ) was powdered under liquid nitrogen and mixed with a chaotropic lysis buffer (RLT, RNeasy Kit, Qiagen). RNA was extracted with Phenol (Ambion, Darmstadt, Germany), purified (RNeasy spin columns, Qiagen) and contaminating DNA was removed (DNase I digestion, Qiagen). The RNA quality was assessed by native agarose gel electrophoresis and ethidium bromide staining.

\subsubsection{Microarray analysis}

Throughout, we followed precisely the recommendations as given by Affymetrix (Affymetrix, St. Clara, USA). From each sample, $5 \mu \mathrm{g}$ total RNA was used for the amplification and labeling reactions. The fragmented cRNA was hybridized for $16 \mathrm{~h}$ at $45{ }^{\circ} \mathrm{C}$ to GeneChip ${ }^{\circledR}$ Bovine Genome Arrays (Affymetrix). The Microarrays were scanned at 1.56 micron resolution using the GeneChip Scanner 3000 (Affymetrix).

\subsection{Microarray data analysis}

Bioinformatic data analysis was done in three steps, including first a quality control of all arrays, next preprocessing of all arrays regarding background correction, normalization and establishing a summary for all probe sets. As a last step, all differentially expressed microarrays were identified.

Quality control, data preprocessing and statistical analysis were performed using the $\mathrm{R}$ statistical language $^{2}-$ employing previously described methods $[4,5]$. After quality control, all arrays could be used for further analysis. Background correction was performed using GCRMA [33], normalization by

\footnotetext{
${ }^{1}$ Supplementary material is available at www. vetres.org

${ }^{2}$ Bioconductor Packages, www.bioconductor.org
} 
quantile normalization, and summary measures for probe sets were obtained by median polish.

Affymetrix IDs were mapped to the pertinent gene symbols based on the assignments available from the Ensemble database, and mean values over all relevant Affymetrix IDs were calculated. We considered for each animal always both, infected and uninfected quarters. Hence, a paired $t$ test was used to assess statistically significant differentially expressed genes $(p=0.05)$. These test results were adjusted for multiple testing using the false discovery rate (FDR), $q$-value method [27]. Data from challenged MEC cultures were analyzed accordingly. Differentially expressed genes were considered if their FDR $q$-value was $\leq 0.05$ in the case of the udder samples, while it was 0.2 for the MEC data. Data were filtered for a foldchange of $>2$-fold.

Human orthologs of regulated bovine genes are based on unpublished data from Hintermair $\mathrm{V}^{3}$. Gene ontology information for regulated genes was obtained using the Ingenuity Pathway Analysis (IPA 7.0) software ${ }^{4}$.

The degree and significance of the correlation between fold changes, as determined in the microarray analysis and those determined by quantitative PCR was evaluated with the Pearson Moment Correlation, using the SigmaStat 3.5 software (Systat Software Inc., San Jose, CA, USA).

\section{RESULTS}

\section{1. qRT-PCR confirm microarray results}

We evaluated the reliability of the microarray based measurements of mRNA abundance with quantitative real-time RT-PCR using the udder samples. Six up regulated and three down regulated genes were selected (cf. Supplementary Tab. $\mathrm{S1}^{1}$ ) and their mRNA concentrations were measured in all samples from the four uninfected controls and four $24 \mathrm{~h}$ infected quarters. The extent of regulation as measured in the microarray determinations correlates favorably with that calculated from the qRT-PCR measurements. The degree of correlation for the 36 data points was $R=0.92(p<0.0001)$.

\footnotetext{
${ }^{3}$ Comparative Analysis of Bos taurus and Homo sapiens DNA Microarrays, Master Thesis, Ludwig Maximilian University Munich, Germany, 2007.

${ }^{4}$ Ingenuity Systems, www.ingenuity.com.
}

\subsection{Characterization of purity and physiological responses of pbMEC}

Anti cytokeratin-18 antibody was applied in immunohistochemistry analysis to specifically visualize luminal epithelial cells. Almost all of the cells in our pbMEC preparations were decorated by this antibody confirming the luminal epithelial nature of our preparations (Fig. 1). Myoepithelial cells surrounded the alveoli in the udder in situ and therefore were quite likely to contaminate pbMEC preparations. Myoepithelial cells are characterized by the presence of smooth muscle actin. Detection of this molecule with a specific antibody showed that only few myoepithelial cells contaminated our cultures (Fig. 1). Hence, the luminal mammary epithelial cell was the dominant cell type in our pbMEC cultures.

We monitored the effect of repeatedly repassaging the pbMEC upon their immune responsiveness (Tab. I). Using the extent of bacteria induced expression of the Lingual Antimicrobial Peptide (LAP)-encoding gene as an indicator, we found that already the second passage lowered by almost an order of magnitude the level of stimulation dependent increased LAP mRNA concentration in the cultures. A complete loss of LAP expression in pbMEC occurred on the third passage. Thus, only short-time subcultures of pbMEC are acceptable to analyze pathogen-dependent gene regulation.

\subsection{E. coli most prominently increases in pbMEC the mRNA abundance of factors contributing to Innate Immunity}

Challenging pbMEC for $24 \mathrm{~h}$ with heat inactivated $E$. coli increased the mRNA abundances from such genes known to contribute to inflammatory activation of the immune response, or from known effectors of Innate Immunity, such as beta-defensins (Tab. II, Supplementary Tab. S2 ${ }^{1}$ ). Increased signal intensities were measured on 334 different probe sets, while only 39 probe sets revealed decreased signals. These probe sets represented 278 and 38 annotated genes (up- and down-regulated, respectively; Tab. II and Supplementary 
PbMEC

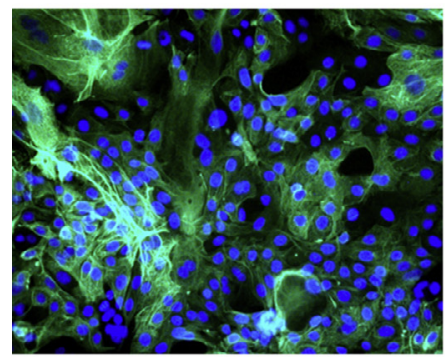

$$
\text { anti-Cy18 }
$$
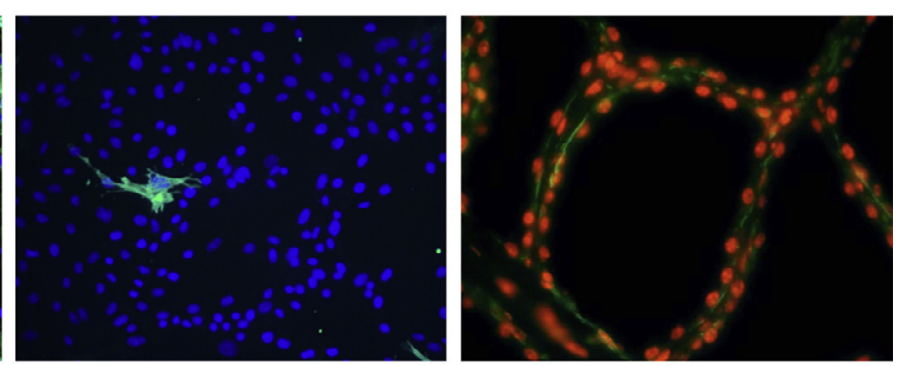

anti-Actin

Figure 1. Validation of cell types in pbMEC cultures. pbMEC cultures were stained with antibodies against cytokeratin 18 (anti-Cy18) or smooth muscle actin (anti-Actin). The udder section (right) was stained with anti-actin to show the in situ arrangement of myoepithelial cells. Nuclei were stained in tissue cultures with DAPI and with ethidium bromide in udder sections.

Table I. Alteration of E. coli induced* LAP-gene expression during subculturing of pbMEC derived from two different animals after $24 \mathrm{~h}$.

\begin{tabular}{lcclcc}
\hline Passage & \multicolumn{2}{c}{ Animal 1 } & & \multicolumn{2}{c}{ Animal 2 } \\
\cline { 2 - 3 } \cline { 5 - 6 } & Control & Induced & & Control & Induced \\
\hline 1 & $1^{* *}$ & 615 & & 1.4 & 536 \\
2 & 0.6 & 71 & & 1 & 150 \\
3 & nil & nil & & 0.04 & 7.5 \\
\hline
\end{tabular}

${ }^{*}$ Challenge was for $24 \mathrm{~h} ;{ }^{* *}$ fold changes of the mRNAconcentration relative to that of the un-induced, not passaged culture from animal one set as 1 .

Tab. $\mathrm{S} 2^{1}$ ) from which human orthologs are known. For biological pathway analyses, we used the designations of the human homologues of the regulated genes because more comprehensive biological information is available for human genes than for those from cattle.

Most strongly induced genes were found to be involved in inflammatory response and pathogen defence like serum amyloid A 3 (SAA3, 1070-fold increased), chemokine (C-C motif) ligand 5 (CCL5, 868-fold increased), and lingual antimicrobial peptide (LAP, 424-fold increased).
Applying the IPA software to the data revealed that important immune response pathways are regulated in response to E. coli challenge. For instance, eleven of the regulated genes are associated to Interferon signaling. These comprise the $2^{\prime}, 5^{\prime}$-oligoadenylate synthetase OAS1, myxovirus resistance MX2/MX1, and the interferon induced transmembrane protein 1 IFITM1. Sixteen of the up regulated genes contribute to NF- $\kappa \mathrm{B}$ signaling, including NF- $\kappa B$ factor RELB; NF- $\kappa B$ inhibitor alpha, NFKBIA; mitogen-activated protein kinase 8 , MAP3K8; CD40; and TLR2. Nine of the up regulated genes are involved in antigen presentation, comprising factors of the major histocompatibility complex, such as HLA-DRA, HLA-DRB1, HLA-A, HLA-DMB, HLADMA, CD74, as well as factors important for proteolytic processing within the proteasome subunits, such as PSMB9; PSMB8; and the transporter TAP1.

Six of the 38 down regulated genes are connected to lipid metabolism. These include the acyl-CoA synthetase medium-chain family member (ACSM1/BUCS1, 4.2-fold decreased), hydroxyprostaglandin dehydrogenase 15-(NAD) (HPGD, 3-fold decreased) and apolipoprotein D (APOD, 2.6-fold decreased). 
Table II. E. coli regulated pbMEC genes, ranked according to the extent of changes in the mRNA concentration.

\begin{tabular}{|c|c|c|}
\hline Gene Symbol & Description & Fold change \\
\hline \multicolumn{3}{|c|}{ (A) Up-regulated (top-20 stimulated) } \\
\hline SAA3 & serum amyloid A 3 & 1070.4 \\
\hline$\underline{\mathrm{CCL}}^{*}$ & chemokine (C-C motif) ligand 5 & 867.7 \\
\hline$\underline{\mathrm{LAP}}$ & lingual antimicrobial peptide & 423.7 \\
\hline$\overline{\mathrm{MX}}$ & myxovirus (influenza virus) resistance 2 & 366.6 \\
\hline RSAD2 & radical S-adenosyl methionine domain containing 2 & 311.9 \\
\hline CCL20 & chemokine (C-C motif) ligand 20 & 311.3 \\
\hline$\underline{\text { IL8 }}$ & interleukin 8 & 256.5 \\
\hline- & —Bt.17195.1.A1_at ${ }^{\mathrm{a}}$ & 223.5 \\
\hline ISG12(A) & similar to putative ISG12(a) protein & 206.9 \\
\hline$\underline{\mathrm{IFI} 44}$ & interferon-induced protein 44 & 202.1 \\
\hline$\underline{\mathrm{HP}}$ & haptoglobin & 152.9 \\
\hline IFI6 & interferon, alpha-inducible protein 6 & 108.8 \\
\hline$\underline{\mathrm{IFI} 44}$ & interferon-induced protein 44 & 102.3 \\
\hline$\overline{\mathrm{RTP} 4}$ & receptor (chemosensory) transporter protein 4 & 97.9 \\
\hline$\underline{\mathrm{IFI} 44}$ & interferon-induced protein 44 & 96.0 \\
\hline PLAC8 & placenta-specific 8 & 95.0 \\
\hline$\underline{\mathrm{IL} 1 \mathrm{~B}}$ & interleukin 1 , beta & 76.6 \\
\hline$\overline{\mathrm{IFI} 44}$ & Interferon-induced protein 44 & 71.7 \\
\hline$\overline{\text { MRM1 }}$ & mitochondrial rRNA methyltransferase 1 homolog & 65.3 \\
\hline$\underline{\text { CCL2 }}$ & chemokine (C-C motif) ligand 2 & 63.6 \\
\hline \multicolumn{3}{|c|}{ (B) Down-regulated (20 most-down regulated) } \\
\hline ACSM1 & acyl-CoA synthetase medium-chain family member 1 & -5.2 \\
\hline RASL12 & RAS-like, family 12 & -5.0 \\
\hline MATN2 & matrilin 2 & -3.6 \\
\hline- & — Bt.24328.1.S1_at & -3.4 \\
\hline FMOD & fibromodulin - & -3.3 \\
\hline HPGD & hydroxyprostaglandin dehydrogenase 15-(NAD) & -3.2 \\
\hline - & —Bt.20861.1.A1_at & -3.0 \\
\hline - & —Bt.14122.1.A1_at & -2.9 \\
\hline HPGD & hydroxyprostaglandin dehydrogenase $15-(\mathrm{NAD})$ & -2.7 \\
\hline APOD & apolipoprotein D & -2.6 \\
\hline ENPP3 & ectonucleotide pyrophosphatase/phosphodiesterase 3 & -2.5 \\
\hline GYPC & glycophorin C (Gerbich blood group) & -2.5 \\
\hline LOC788422 & hypothetical protein LOC788422 & -2.5 \\
\hline CITED1 & $\mathrm{Cbp} / \mathrm{p} 300$-interacting transactivator & -2.4 \\
\hline TMEM117 & transmembrane protein 117 & -2.4 \\
\hline - & —Bt.12819.1.S1_at & -2.4 \\
\hline $\mathrm{ZCCHC7}$ & zinc finger, $\mathrm{CCHC}$ domain containing 7 & -2.4 \\
\hline PDK4 & pyruvate dehydrogenase kinase, isozyme 4 & -2.3 \\
\hline SELENBP1 & selenium binding protein 1 & -2.3 \\
\hline MED11 & mediator complex subunit 11 & -2.3 \\
\hline
\end{tabular}

${ }^{*}$ Underlined, IPA category Inflammatory Response.

${ }^{a}$ Non annotated probe sets are specified by the respective Affymetrix identifier. 


\subsection{E. coli elicited acute mastitis most strongly induces the expression of effector genes of Innate Immunity in the udder}

In order to evaluate the adequacy of MEC as models reflecting udder relevant immune properties, we recorded in the udder all expressed genes that are regulated as a consequence of acute mastitis. We used the same Affymetrix arrays for this analysis. Comparison of these data with the lists of regulated genes from the bovine MEC model should allow elucidating the MEC-specific role in the immune defence of the udder. To this end, we analyzed the mastitis regulated genes from the udder quarters collected $24 \mathrm{~h}$ after experimental infection with the same live $E$. coli pathogen strain as used for the pbMEC analysis. We separately analyzed for this overview the samples from four cows infected for $24 \mathrm{~h}$ with the live pathogen. All these udder quarters featured acute mastitis. RNA from the uninfected quarters of the same animals served as controls. Applying $\geq 2$-fold change in mRNA abundance and a FDR $\leq$ 0.05 as criterion for the subsequent analysis, we found that acute mastitis caused by this pathogenic E. coli strain increased the concentrations of mRNA moieties as detected on 1893 probe sets (Supplementary Tab. S3 $\mathrm{A}^{1}$ ). These include 1412 annotated genes from which human orthologs are known. Intensities were found lowered on 1288 probe sets, including 975 annotated genes (Supplementary Tab. $\mathrm{S} 3 \mathrm{~B}^{1}$ ). The fully inflamed udder regulated a larger number of genes than $E$. coli challenged pbMEC (supplementary Fig. S1A ${ }^{1}$ ). We found that 143 and 15 probe sets measured mRNA from such genes that were up and down regulated in both sources, in the udder as well as in pbMEC.

The most strongly increased mRNA concentrations were recorded from beta-defensinencoding genes (BNBD-4, LAP, DEFB1, and BNBD-9-LIKE; Supplementary Tab. $\mathrm{S} 3^{1}$ ), indicating a tremendous activation of the synthesis of bactericidal $\beta$-defensins. The mRNA concentrations of other well known effectors of Innate Immunity, including interleukin 8 receptor alpha (IL8RA), inducible nitric oxide synthase (NOS2A), and haptoglobin (HP) were also very strongly enhanced (Tab. III, Supplementary Tab. $\mathrm{S} 3^{1}$ ).

The list of udder regulated mRNA also includes many chemokines important for recruitment of lymphocytes, granulocytes and monocytes like CCL20, CCL3, CCL4, CXCL2, CXCL5, IL8, and CCL5. The concentration of the CCL5-encoding mRNA is only found to be 44-fold increased in the udder, just a small fraction $(\sim 5 \%)$ of that increase as observed in the MEC model. The infected udders revealed increased expression of genes encoding leukocyte specific surface proteins, such as CD80 and CD48 molecules, the colony stimulating factor 3 receptor (CSF3R), and Interleukin 2 Receptor gamma (IL2RG). Further, arachidonate 5-lipoxygenase-activating protein (ALOX5AP), which is critical in activating ALOX5 as the most prominent lipoxygenase of myeloid cells, is strongly increased (39-fold) in infected udders. All these genes were not expressed, neither in challenged nor in un-challenged pbMEC. Hence, these gene products indicate that leucocytes were recruited into the infected udder quarters.

Also, acute mastitis increased the mRNA concentrations of two nuclear factors of kappa light polypeptide gene enhancers in B-cells (NFKB1, -B2, 3.7 and 17.0-fold, respectively) and the jun oncogene (JUN, 4.0-fold), known key regulators of immune cell functions. The mRNA abundance of several NF- $\kappa B$-Inhibitors was also found to be increased (NFKBI-A, -B, $-\mathrm{D},-\mathrm{E},-\mathrm{Z})$. The mRNA concentrations of GAP$\mathrm{DH}$ and several tubulins were clearly increased (+ 3-fold, + 7-3-fold, respectively), indicating that these mRNA should not be considered as "unchanging" internal standards in such experiments.

The mRNA with lowered concentrations include those of 77 factors contributing to the functional category Lipid Metabolism (cytochrome P450 subfamily 2B6; CYP2B6, microsomal triglyceride transfer protein; MTTP, lipoprotein lipase; LPL, apolipoprotein D; APOD, fatty acid synthase; FASN, butyrophilin, subfamily 1 , member A1; BTN1A1 -38 -7-fold). 
Table III. Comparison of challenge induced Inflammatory Response (IPA category) between pbMEC and infected udders.

\begin{tabular}{lllr}
\hline Gene Symbol & \multicolumn{1}{c}{ Description } & \multicolumn{2}{c}{ Fold change } \\
\cline { 2 - 4 } & & Udder & pbMEC \\
\hline IL8RB & interleukin 8 receptor, beta & 607.6 & \\
CCL20 & chemokine (C-C motif) ligand 20 & 514.8 & 311.3 \\
CCL4L & chemokine (C-C motif) ligand 4-like & 389.4 & \\
CCL3L1 & chemokine (C-C motif) ligand 3-like 1 & 356.9 & \\
IL1RN & interleukin 1 receptor antagonist & 242.9 & 2.3 \\
MEFV & Mediterranean fever & 236.4 & 423.7 \\
DEFB4 & defensin, beta 4 & 201.8 & 11.8 \\
S100A9 & S100 calcium binding protein A9 & 182.7 & \\
CD69 & CD69 molecule & 157.5 & \\
CCR1 & chemokine (C-C motif) receptor 1 & 146.7 & \\
GPX2 & glutathione peroxidase 2 (gastrointestinal) & 143.5 & \\
TNFAIP6 & tumor necrosis factor, alpha-induced protein 6 & 138.4 & \\
SAA4* & serum amyloid A4 & 135.7 & \\
S100A12 & S100 calcium binding protein A12 & 126.1 & \\
IL1B & interleukin 1, beta & 113.9 & 47.3 \\
IL1R2 & interleukin 1 receptor, type II & 106.2 & \\
TREM1 & triggering receptor expressed on myeloid cells 1 & 98.6 & \\
IGSF6 & immunoglobulin superfamily, member 6 & 86.2 & \\
IL1A & interleukin 1, alpha & 84.4 & 8.3 \\
CD55 & CD55, decay accelerating factor for complement & 69.6 & \\
\hline
\end{tabular}

${ }^{*}$ Note that SAA3 is the most strongly up regulated gene in pbMEC (cf. Tab. II).

\subsection{The fraction of $E$. coli regulated "Inflammatory Response" genes is larger in MEC than in the udder}

We examined those regulated genes, which belong to the IPA functional category Inflammatory Response in order to evaluate more closely the immune capacity of our MEC model. Human orthologs of the respective functional category were identified from 82 genes found up regulated by the E. coli challenge in pbMEC (Tab. III, Supplementary Fig. S1B; Tab. $4^{1}{ }^{1}$ ). In contrast, the expression of 234 genes with known human orthologs appeared to be up regulated in the E. coli infected udders.

Those 82 up regulated Inflammatory Response genes in E. coli stimulated pbMEC, representing $30 \%$ of all those genes with increased mRNA abundance in this cell system. In contrast, we found that 234 genes of the same functional category revealed increased mRNA abundance in infected udders, representing $17 \%$ from the entire 1412 udder expressed genes featuring infection related increased mRNA concentrations. These data show that genes contributing to the inflammatory response represent a larger fraction of all positively regulated genes in MEC than observed in the whole udder. This underscores the immune relevance of that cell type.

Forty-eight inflammatory response genes were found to be commonly up regulated in both pbMEC and the infected udder. These comprise genes encoding chemokines important for leukocyte recruitment, such as CCL20, CCL5, CCL2, IL8, CXCL2, CXCL3, CXCL5, and CX3CL1, also known as fractalkine. However, several genes featured much stronger increased mRNA abundance in $E$. coli challenged pbMEC than that found in the udder as caused by acute mastitis. Examples are Interleukin 8 (257 vs. 58-fold, pbMEC vs. 
udder, respectively), CCL5 (867-fold vs. 43-fold), and CCL2 (46-fold vs. 14-fold). These data collectively suggest that the isolated bovine MEC is in principal capable to eventually elicit much stronger alarm signals to recruit monocytes (CCL5, CCL2) or activate B-lymphocytes than that observed in the heavily inflamed udder.

\subsection{Functionally concerted expressional regulation of complement factors in infected udders, but not in MEC}

The complement system represents a complex network of functionally interdependent factors. Hence, we took this as an example to scrutinize on the adequacy of pbMEC as a model to properly reflect regulation of relevant immune networks.

Infected udders showed a differentiated transcriptional regulation of the complement factors (Fig. 2). The mRNA concentrations of Complement Factor B (CFB), contributing to the alternative pathway of complement activation were strongly increased (19.7-fold). Complement inhibitors were also increased, such as the membrane bound inhibitor Decay-Accelerating Factor 1 (DAF, 69.6-fold) or Complement Component C1q-Binding Protein (C1qBP, 1.8-fold) preventing $\mathrm{C} 1$ activation.

Mastitis in the udder, however, significantly down regulated the mRNA concentrations of the whole group of factors belonging to the $\mathrm{C} 1$ complex. These are required for the antibody mediated complement activation and include $\mathrm{C} 1 \mathrm{qA}, \mathrm{C} 1 \mathrm{qB}, \mathrm{C} 1 \mathrm{~s}$, and $\mathrm{C} 1 \mathrm{r}$ (between 3.2 to 1.6-fold decreased). We also found lowered mRNA concentrations of factors forming the Membrane Attack Complex (MAC) of the lytic pathway (C6, C7, (60.7-fold and 11.5-fold respectively)).

Mastitis also decreased the mRNA concentrations of such factors that inhibit the alternative pathway. Examples are the fluid phase complement inhibitor, factor $\mathrm{H}(\mathrm{CFH}$, (8.6-fold)) and the Serpin Peptidase Inhibitor clade G, member 1 (SERPING1, 3.5-fold).

In pbMEC, however, only a subset of these factors appears to be regulated. Moreover this features only unidirectional increased mRNA concentrations (Fig. 2). The mRNA abundances of those factors encoding CFB (17.4-fold), C2 (14.4-fold), and C3 (3.8-fold) were strongly and significantly increased. C1s (1.7-fold) was moderately increased. The complement components $\mathrm{C} 2$ and $\mathrm{C} 3$ were regulated and stimulated in pbMEC, but not in the udder. Hence, MEC are in principle competent to synthesize these complement factors. The mRNA of most of those factors found only to be regulated in udder were absent in either un-stimulated or stimulated pbMEC (C1QA, C1QB, CFH, C6, $\mathrm{C7}$ ) indicating that our pbMEC model for this cell type is unable to synthesise these proteins.

\section{DISCUSSION}

Our study provides a comprehensive survey of genes found to be regulated by $E$. coli elicited mastitis in the udder of the cow and in bovine MEC models after a strong pathogenic stimulus. While attempting to keep the stimuli as similar as possible, we challenged the pbMEC with heat killed pathogens of the same $E$. coli strain, from which live pathogens were infused into healthy lactating udders for the experimental infections. However, the pbMEC challenge differed from the in vivo infections in several significant ways. First, no pathogen derived virulence factors were present. This was tolerated in order to provide standardized and reproducible conditions for the pbMEC challenge and yet deliver an immune alert through a collection of Pathogen Associated Molecular Patterns quite similar to that encountered by the host during the experimental udder infections. Hence, the pbMEC were not confronted with pathogen derived virulence factors. Second, the time course differed markedly between both challenges. The challenge for the MEC was delivered at the start of the experiment with the same intensity $\left(10^{7} / \mathrm{mL}\right.$ of $E$. coli particles $(\sim 30 \mathrm{MOI}))$ for all cells. The in vivo infection experiments, however, with as few as 500 pathogens per infected udder quarter, conceivably suffered from a severe lag period before the immune alert could effectively be recognized by the host. Thus, the inflammation kinetics was certainly quite different in both models. However, in both challenged udders and pbMEC 
Classical pathway

C1 activation

Factors $\downarrow$ C1qA, C1qB, C1s, C1r $\quad \mathbf{C} 1 \mathrm{r}$

Inhibitors

C1qBP

SERPING1

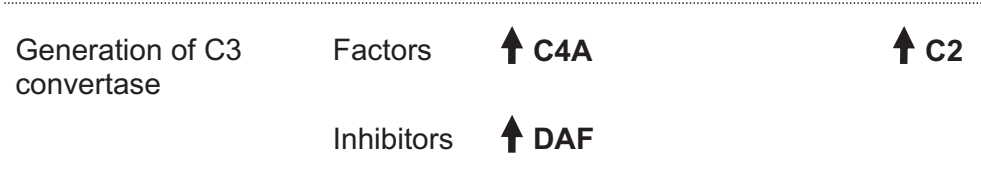

$\begin{array}{lll}\begin{array}{l}\text { Generation of } \mathrm{C5} \\ \text { convertase }\end{array} & \text { Factors } & \mathbf{4} \text { C3 } \\ & \text { Inhibitors }\end{array}$

\begin{tabular}{|c|c|c|c|}
\hline \multirow[t]{2}{*}{ Alternative pathway } & Factors & 个 CFB & A CFB, C3 \\
\hline & Inhibitors & $\begin{array}{l}\text { DAF } \\
\text { Factor H }\end{array}$ & \\
\hline Lytic pathway & Factors & $\downarrow \mathrm{C} 6, \mathrm{C} 7$ & \\
\hline & Inhibitors & $\checkmark$ CD59 & \\
\hline
\end{tabular}

Figure 2. Expressional regulation of complement genes, E. coli infected udders or E. coli stimulated pbMEC. Genes with a $\geq 1.5$-fold expression change are listed. Genes with a $\geq 2$-fold expression change are in bold letters. Arrows indicate up- or down-regulation of mRNA abundance. Udders (infected) or pbMEC (stimulated) were both challenged for $24 \mathrm{~h}$.

we found heavily increased mRNA concentrations of acute phase proteins, such as HP, CFB, and SAA, indicating that both models were in comparable and late stages of inflammation.

We firmly establish the principle suitability and some limitations of this MEC model for the analysis of cell type-specific mechanisms involved in the activation of mammary immune functions. Last, and as a somewhat unexpected key observation we recognize that acute mastitis increases in the udder the expression of factors of the alternative pathways of the complement system, but down regulates numerous components of the classical pathway and of the MAC.

\subsection{Immune-relevant key functions of MEC are recruiting immune cells and the synthesis of bactericidal molecules}

We report here that the E. coli challenged MEC model strongly increases the abundance of mRNA molecules encoding well known immune factors whose expression is regulated by TLR signaling (CCL5, IL6, IL1, NOS2A). 
The MEC strongly up regulates an orchestra of chemokines like CCL20, IL8, CCL2, CXCL5 and CXCL2 in response to pathogen challenge. This observation indicates that upon recognizing the pathogen, bovine MEC are able to send out a strong signal of chemokines into the organism to recruit cellular factors of immune defence (e.g. monocytes, granulocytes, macrophages) from the blood stream into the infected mammary gland. In keeping with our identification of MEC as a major source of the enhanced synthesis of these factors, it has often been reported that infections with $E$. coli or gram negative pathogens strongly induce the secretion of such chemokines/cytokines (IL8, TNF- $\alpha$ ) into the milk. This, however, occurs only with infected udder quarters $[1-3,22$, 23]. Hence, these chemokines conceivably also exert locally restricted functions. IL8 and CCL2 were both shown to eventually induce locally restricted polarized diapedesis of neutrophils across epithelia and endothelia [14].

Increased synthesis of molecules with bactericidal functions ( $\beta$-defensin, Nitric Oxide Synthase), as well as of coating factors (HP, SAA) are the second very clearly discernible immune function of MEC. We have previously already demonstrated that MEC may eventually express the $\beta$-defensin 5 gene [11]. Further, expressional up regulation of genes encoding enzymes for eicosanoid synthesis and down regulation of an enzyme which promotes prostaglandin degradation in challenged MEC (PDGES, ALOX15B, and HPGD, respectively) demonstrates that this cell type is a significant source of prostaglandins and anti-inflammatory lipoxins in the udder. Hence, the primary bovine MEC could be considered as an adequate model to study the pathogen-specific activation of all those genes.

pbMEC surprisingly down-regulate few genes. Notably, no casein-encoding genes were detected in this regard, albeit casein-synthesis was shown to be blunted in the udder by E. coli infections [31]. However, our MEC model did not reflect that lactation specific phenotype as it is displayed by MEC in situ within the milk parenchyma of the lactating udder. Only parameters of milk fat synthesis (fatty acid synthase) and fatty acid transport (fatty acid binding protein 4) are expressed in pbMEC and are down regulated by the E. coli stimulus.

\subsection{The pbMEC model does not properly reflect the mastitis induced regulation of chemokines and of the Complement System in the udder}

The pbMEC cultures apparently do not properly reflect the extent of increased expression of a variety of key mediators of pro-inflammation and of the complement system. The $E$. coli challenge resulted in a $>860$-fold increased mRNA concentration of CCL5 (RANTES) in pbMEC, while we found only a 44-fold increase for the same parameter in the acutely E. coli infected udder. This disproportioned increase shows that the MEC in principle has the capacity to indeed elicit a much stronger signal than that observed in vivo in the udder. Conceivably, the immune relevant activity of MEC is regulated and balanced within the udder by factors delivered from other cell types. We already indicated the minimal up regulation of Interleukin 1 receptor antagonist (IL1RN) mRNA in pbMEC (2-fold) compared to the infected udder, where mastitis increased its mRNA abundance $>240$ fold. Moreover, it is known for example that a key down regulator of inflammation, Interleukin 10 is not expressed in MEC [28]. Although we found its mRNA concentration $>50$-fold increased in those $24 \mathrm{~h}$ infected udder quarters that have been used in this analysis [35], we could not detect IL-10 mRNA molecules in our pbMEC cultures. Hence, controls dampening inflammation may be missing in the MEC model cells.

Indications for deregulated immune functions in pbMEC are also evident considering the complement cascade. Both the extent and direction of regulation are different in $E$. coli challenged pbMEC compared to the udders featuring heavy infections with the same pathogen. We found a strong enhancement of the expression of the C2-encoding gene (14-fold increased) in pbMEC, although we did not detect changes in the mRNA of this gene in 
our infected udder samples. E. coli up-regulated in pbMEC genes encoding the $\mathrm{C} 1$ factor family; however, mastitis lowered their abundance in the infected udder of the cow.

\section{3. $E$. coli elicited mastitis down regulates in the udder the Classical Pathway and MAC of the complement system}

Mastitis eventually reprograms within $24 \mathrm{~h}$ the udder from full lactation to defence, including a complete shut down of casein synthesis [31]. Hence, our holistic microarray profiling of the mastitis induced transcriptional changes are also records of an almost complete reprogramming of the entire metabolism within the udder. We focused our interest here on the regulation of factors of the complement system extracting from this very complex data information concerning only a specific subset of in part functionally interdependent factors.

The structure and relevance of the complement system for mammary immune defence has recently been reviewed [20,21]. We found that mastitis down regulates all such factors belonging to the classical, antibody mediated pathway of complement activation. Binding of $\mathrm{C} 1 \mathrm{q}$ to the complement binding site on domain three of the immunoglobulin heavy chain triggers this pathway. Milk was reported to have very low concentrations of $\mathrm{Clq}$ and it was thus concluded that the classical pathway of complement activation would not operate in the udder [20]. Our data augment this observation and moreover show that mastitis indeed even down regulates both, the factors of the $\mathrm{C} 1$ family and those of the MAC components C6 and C7. The down regulation of the immunoglobulin mediated activation of the complement which indeed is an important effector function of immunoglobulins may contribute a new aspect to the well known difficulty encountered in attempts to protect the udder from infection via active immunization [32].

However, mastitis strongly increases the expression of CFB a factor important in the activation of the alternative complement pathway. This indicates that in the udder, the complement mediated pathogen recognition occurs mainly in an unspecific manner. CFB is crucial for the generation of $\mathrm{C} 3$ and $\mathrm{C} 5$ convertases of the alternative pathway, generating opsonins (C3b), anaphylatoxins (C3a, C5a), and chemotactic fragments (C5a). These promote inflammation as well as activate and recruit neutrophils and macrophages into the infected udder. Further CFB is known to activate bovine monocytes and neutrophils [25].

Our data on the regulation of the complement system during mastitis altogether underscore the importance of recruiting effector cells into the udder. Combining this with the demonstration that the MEC massively increase the mRNA concentrations of a variety of chemokines known to recruit immune cells indicates that an E. coli infection of the udder elicits a very strong signal into the host to send effectors into the infected udder quarter. In addition to their role as sentinel cells of the milk parenchyma, MEC also exert bactericidal functions. E. coli induces in these cells the synthesis of the bactericidal $\beta$-defensins, but also that of highly aggressive bactericidal radicals that are produced from the iNOS gene products. Both types of molecules, $\beta$-defensins and $\mathrm{NO}_{\mathrm{x}}$ radicals constitute bactericidal weapons proprietary to MEC.

Acknowledgements. We are grateful for the technical support from Angelika Deike, Anne Berndt and Bärbel Pletz. This work was supported by the DFG through the Researcher Group FOR585 (grant Se 326/14-2). The European Community through the EADGENE network-of-excellence also contributed to this work. The MORST of New Zealand supported this analysis through the Julius-von-Haast award to HMS and the AgResearch (Hamilton, New Zealand).

\section{REFERENCES}

[1] Bannerman D.D., Paape M.J., Goff J.P., Kimura K., Lippolis J.D., Hope J.C., Innate immune response to intramammary infection with Serratia marcescens and Streptococcus uberis, Vet. Res. (2004) 35: 681-700.

[2] Bannerman D.D., Paape M.J., Lee J., Wei Z., Xin H., Jayne C., Rainard P., Escherichia coli and Staphylococcus aureus elicit differential innate immune responses following intramammary infection, Clin. Diagn. Lab. Immunol. (2004) 11:463-472. 
[3] Blum J.W., Dosogne H., Hoeben D., Vangroenweghe F., Hammon H.M., Bruckmaier R.M., Burvenich C., Tumor necrosis factor-alpha and nitrite/nitrate responses during acute mastitis induced by Escherichia coli infection and endotoxin in dairy cows, Domest. Anim. Endocrinol. (2000) 19:223-235.

[4] Bolstad B.M., Irizarry R.A., Astrand M., Speed T.P., A comparison of normalization methods for high density oligonucleotide array data based on variance and bias, Bioinformatics (2003) 19:185-193.

[5] Bolstad B.M., Collin F., Brettschneider J., Simpson K., Cope L., Irizarry R.A., Speed T.P., Quality assessment of Affymetrix GeneChip data, in: Gentleman R., Carey V., Huber W., Irizarry R., Dudoit S. (Eds.), Quality assessment of Affymetrix GeneChip data in bioinformatics and computational biology solutions using $\mathrm{R}$ and Bioconductor, Chapter 3, Springer, 2005.

[6] Burvenich C., Paape M.J., Hill A.W., Guidry A.J., Miller R.H., Heyneman R., et al., Role of the neutrophil leucocyte in the local and systemic ractions during experimentally induced $E$. coli mastitis in cows immediately after calving, Vet. Q. (1994) 16:45-50.

[7] Burvenich C., Van Merris V., Mehrzad J., DiezFraile A., Duchateau L., Severity of E. coli mastitis is mainly determined by cow factors, Vet. Res. (2003) 34:521-564.

[8] De Haas Y., Veerkamp R.F., Barkema H.W., Grohn Y.T., Schukken Y.H., Associations between pathogen-specific cases of clinical mastitis and somatic cell count patterns, J. Dairy Sci. (2004) 87:5-105.

[9] Dosogne H., Vangroenweghe F., Barrio B., Rainard P., Burvenich C., Decreased number and bactericidal activity against Staphylococcus aureus of the resident cells in milk of dairy cows during early lactation, J. Dairy Res. (2001) 68:539-549.

[10] Erskine R.J., Eberhart R.J., Hutchinson L.J., Spencer S.B., Campbell M.A., Incidence and types of clinical mastitis in dairy herds with high and low somatic cell counts, J. Am. Vet. Med. Assoc. (1988) 192:761-765.

[11] Goldammer T., Zerbe H., Molenaar A., Schuberth H.J., Brunner R.M., Kata S.R., Seyfert H.M., Mastitis increases mammary mRNA abundance of beta-defensin 5, toll-like-receptor 2 (TLR2), and TLR4 but not TLR9 in cattle, Clin. Diagn. Lab. Immunol. (2004) 11:174-185.

[12] Hensen S.M., Pavicic M.J., Lohuis J.A., de Hoog J.A., Poutrel B., Location of Staphylococcus aureus within the experimentally infected bovine udder and the expression of capsular polysaccharide type 5 in situ, J. Dairy Sci. (2000) 83:1966-1975.
[13] Huijps K., Lam T.J., Hogeveen H., Costs of mastitis: facts and perception, J. Dairy Res. (2008) $75: 113-120$

[14] Kruger S., Brandt E., Klinger M., Kruger S., Kreft B., Interleukin-8 secretion of cortical tubular epithelial cells is directed to the basolateral environment and is not enhanced by apical exposure to Escherichia coli, Infect. Immun. (2000) 68:328-334.

[15] Lahouassa H., Moussay E., Rainard P., Riollet C., Differential cytokine and chemokine responses of bovine mammary epithelial cells to Staphylococcus aureus and Escherichia coli, Cytokine (2007) 38: $12-21$.

[16] Paape M.J., Shafer-Weaver K., Capuco A.V., Van Oostveldt K., Burvenich C., Immune surveillance of mammary tissue by phagocytic cells, Adv. Exp. Med. Biol. (2000) 480:259-277.

[17] Pareek R., Wellnitz O., Dorp R., Burton J., Kerr D., Immunorelevant gene expression in LPSchallenged bovine mammary epithelial cells, J. Appl. Genet. (2005) 46:171-177.

[18] Petzl W., Zerbe H., Gunther J., Yang W., Seyfert H.M., Nurnberg G., Schuberth H.J., Escherichia coli, but not Staphylococcus aureus triggers an early increased expression of factors contributing to the innate immune defense in the udder of the cow, Vet. Res. (2008) 39:18.

[19] Rainard P., Riollet C., Poutrel B., Paape M.J., Phagocytosis and killing of Staphylococcus aureus by bovine neutrophils after priming by tumor necrosis factor-alpha and the des-arginine derivative of C5a, Am. J. Vet. Res. (2000) 61:951-959.

[20] Rainard P., The complement in milk and defense of the bovine mammary gland against infections, Vet. Res. (2003) 34:647-670.

[21] Rainard P., Riollet C., Innate immunity of the bovine mammary gland, Vet. Res. (2006) 37:369-400.

[22] Riollet C., Rainard P., Poutrel B., Cells and cytokines in inflammatory secretions of bovine mammary gland, Adv. Exp. Med. Biol. (2000) 480: 247-258.

[23] Riollet C., Rainard P., Poutrel B., Differential induction of complement fragment C5a and inflammatory cytokines during intramammary infections with Escherichia coli and Staphylococcus aureus, Clin. Diagn. Lab. Immunol. (2000) 7:161-167.

[24] Seegers H., Fourichon C., Beaudeau F., Production effects related to mastitis and mastitis economics in dairy cattle herds, Vet. Res. (2003) 34:475-491.

[25] Sethi M.S., Tabel H., Bb fragment of bovine complement factor B: stimulation of the oxidative 
burst in bovine monocytes, Can. J. Vet. Res. (1990) $54: 410-414$.

[26] Sordillo L.M., Streicher K.L., Mammary gland immunity and mastitis susceptibility, J. Mammary Gland Biol. Neoplasia (2002) 7:135-146.

[27] Storey J.D., A direct approach to false discovery rates under dependence, J. R. Stat. Soc. Ser. B (2002) 64:479-498.

[28] Strandberg Y., Gray C., Vuocolo T., Donaldson L., Broadway M., Tellam R., Lipopolysaccharide and lipoteichoic acid induce different innate immune responses in bovine mammary epithelial cells, Cytokine (2005) 31:72-86.

[29] Swinkels J.M., Hogeveen H., Zadoks R.N., A partial budget model to estimate economic benefits of lactational treatment of subclinical Staphylococcus aureus mastitis, J. Dairy Sci. (2005) 88:4273-4287.

[30] Vangroenweghe F., Rainard P., Paape M., Duchateau L., Burvenich C., Increase of Escherichia coli inoculum doses induces faster innate immune response in primiparous cows, J. Dairy Sci. (2004) 87:4132-4144.

[31] Vanselow J., Yang W., Herrmann J., Zerbe H., Schuberth H.J., Petzl W., Tomek W., Seyfert H.M., DNA-remethylation around a STAT5-binding enhancer in the $\alpha \mathrm{S} 1$-casein promoter is associated with abrupt shut-down of $\alpha \mathrm{S} 1$-casein synthesis during acute mastitis, J. Mol. Endocrinol. (2006) 37:463-477.

[32] Wilson D.J., Grohn Y.T., Bennett G.J., Gonzalez R.N., Schukken Y.H., Spatz J., Comparison of J5 vaccinates and controls for incidence, etiologic agent, clinical severity, and survival in the herd following naturally occurring cases of clinical mastitis, J. Dairy Sci. (2007) 90:4282-4288.

[33] Wu Z.J., Irizarry R.A., Gentleman R., MartinezMurillo F., Spencer F., A model-based background adjustment for oligonucleotide expression arrays, J. Am. Stat. Assoc. (2004) 99:909-917.

[34] Yang W., Molenaar A., Kurts-Ebert B., Seyfert H.M., NF-kappaB factors are essential, but not the switch, for pathogen-related induction of the bovine beta-defensin 5-encoding gene in mammary epithelial cells, Mol. Immunol. (2006) 43:210-225.

[35] Yang W., Zerbe H., Petzl W., Brunner R.M., Gunther J., Draing C., et al., Bovine TLR2 and TLR4 properly transduce signals from Staphylococcus aureus and E. coli, but $S$. aureus fails to both activate NF-kappaB in mammary epithelial cells and to quickly induce TNFalpha and interleukin-8 (CXCL8) expression in the udder, Mol. Immunol. (2008) 45:1385-1397. 